Vol 4 No 2 (2021) 174-186 P-ISSN 2620-295 E-ISSN 2747-0490

DOI: 1047467/elmal.v4i2.535

\title{
Pengaruh Religiusitas, Gaya Hidup, dan Harga terhadap Keputusan Pembelian Produk Busana Muslim di Marketplace
}

\author{
Aldeana Meliani1 ${ }^{1}$ Ahmad Mulyadi Kosim², Hilman Hakiem³ \\ 1,2,3Universitas Ibn Khaldun Bogor \\ aldeana.mln@gmail.com¹, ahmadmulyadi@fai.uika-bogor.ac.id², \\ hilman@fai.uika-bogor.ac.id ${ }^{3}$
}

\begin{abstract}
This study aims to find out how much religiosity, lifestyle, and price influence on the decision to purchase Muslim fashion products on Marketplace. Research using quantitative method by disseminating questionnaires through google-form to Muslim respondents who have purchased Muslim fashion products on Marketplace (Shopee) and domiciled in Jakarta and Bogor. Sampling techniques using purposive sampling method which is part of non probability sampling technique. The number of samples as many as 100 respondents. The results of this study showed that the religious variables did not have a significant effect, but lifestyle variables and prices had a significant effect. Other findings showed that variable $Y$ could be explained by $67.9 \%$ by variable $X$. The remaining 33.1\% was explained by other variables beyond the researchers' discussion.
\end{abstract}

Keywords: Religiosity, Lifestyle, Price, Decision Purchase, Muslim Fashion Product

\begin{abstract}
ABSTRAK
Penelitian ini bertujuan untuk mengetahui seberapa besar pengaruh religiusitas, gaya hidup, dan harga terhadap keputusan pembelian produk busana muslim di Marketplace. Penelitian menggunakan metode kuantitatif dengan cara menyebarkan kuesioner melalui googleform kepada responden beragama Islam yang pernah melakukan pembelian produk busana muslim di Marketplace (Shopee) dan berdomisili di Jakarta maupun Bogor. Teknik pengambilan sampel menggunakan metode purposive sampling yang merupakan bagian dari teknik non probability sampling. Jumlah sampel sebanyak 100 responden. Hasil penelitian ini menunjukkan bahwa variabel religiusitas tidak berpengaruh secara signifikan, namun variabel gaya hidup dan harga berpengaruh secara signifikan. Temuan lain menunjukkan bahwa variabel Y dapat dijelaskan sebesar $67,9 \%$ oleh variabel X. Sisanya sebesar 33,1\% dijelaskan oleh variabel lain diluar pembahasan peneliti.
\end{abstract}

Kata Kunci: Religiusitas, Gaya Hidup, Harga, Keputusan Pembelian, Produk Busana Muslim 




\section{Vol 4 No 2 (2021) 174-186 P-ISSN 2620-295 E-ISSN 2747-0490 DOI: $1047467 /$ elmal.v4i2.535}

\section{PENDAHULUAN}

Perkembangan teknologi informasi dan komunikasi yang semakin pesat telah membawa perubahan yang signifikan terhadap gaya hidup masyarakat. Segala sesuatu yang diinginkan akan dipermudah dengan adanya internet sebagai salah satu pendukung perkembangan teknologi. Pada praktiknya, hal ini dapat dirasakan masyarakat dengan mudahnya belanja kebutuhan tanpa ada interaksi langsung antara pembeli dan penjual.Belanja online terbilang efisien waktu sehingga seringkali dijadikan sebagai suatu alternatif.Terciptanya Marketplace sebagai wadah platform belanja digital dapat menguntungkan semua pihak. Semakin canggih suatu teknologi, maka gaya hidup yang diterapkan semakin berkembang luas dalam kehidupan. Perkembangan teknologi akan selalu dihadirkan dengan kemunculan berbagai macam tren yang berlaku.Gaya hidup dapat merubah sikap seseorang dalam menyikapi tren yang ada. Permasalahan yang terjadi khususnya pada kalangan muslimah, busana muslim yang memenuhi ketentuan syariat Islam seringkali tidak dihiraukan. Fenomena ini disebabkan karena tren busana muslim bernuansa modern telah menjadi pilihan masyarakat. Hal ini cukup menjadi perhatian khususnya pada wanita muslimah dalam hal tata cara berpakaian agar tidak menyimpang dari konsep busana muslim yang sebenarnya hanya karena mengikuti tren semata. Selain aspek gaya hidup dan religiusitas, harga merupakan salah satu aspek terpenting dari elemen bauran pemasaran yang dilibatkan dalam keputusan pembelian produk. Penetapan harga yang selalu dipertimbangkan oleh pelaku usaha akan berpengaruh pada tingkat permintaan konsumen.

\section{LANDASAN TEORI}

\section{Keputusan Pembelian}

Keputusan pembelian merupakan tindakan seseorang baik secara langsung maupun tidak langsung dalam memperoleh suatu produk atau jasa yang dibutuhkan.Pengambilan keputusan adalah langkah yang penting dilakukan sebelum akhirnya produk yang diinginkan jatuh ke tangan konsumen sebagai pemilik barang (Tjiptono, 2014).

Menurut Kotler dan Armstrong (2008) menjelaskan bahwa pada tahap evaluasi, konsumen menentukan peringkat merek dan membentuk niat pembelian.Pada umumnya, keputususan pembelian (purchase decision) konsumen adalah membeli merek yang paling disukai, tetapi dua faktor bisa berada antara niat pembelian dan keputusan pembelian. Faktor pertama adalah sikap orang lain yang dapat mempengaruhi seseorang dan faktor kedua adalah faktor situasional. Konsumen mungkin membentuk niat 


\section{Jurnal Kajian Ekonomi \& Bisnis Islam}

\section{Vol 4 No 2 (2021) 174-186 P-ISSN 2620-295 E-ISSN 2747-0490 DOI: $1047467 /$ elmal.v4i2.535}

pembelian berdasarkan faktor-faktor seperti pendapatan, harga, dan manfaat produk yang diharapkan.Namun, kejadian tak terduga bisa mengubah niat pembelian.

\section{Religiusitas}

Religiusitas adalah suatu simbol sistem keyakinan, nilai, dan perilaku yang memusatkan berbagai persoalan-persoalan duniawi yang keseluruhan maknanya disimpulkan dalam suatu keyakinan hakiki. Seseorang dengan tingkat keyakinan yang tinggi akan mengubah perilakunya sesuai dengan ajaran agama dalam bersosialisasi dengan masyarakat sekitar (Miatun, 2020).

Religiusitas dapat dikatakan sebagai suatu sikap atau perilaku ketaatan dan pemahaman seseorang terhadap agama yang diyakini sehingga ia bertindak sesuai dengan aturan dan kewajiban agama tersebut dalam kehidupannya. Pada dasarnya, penerapan ajaran religius dari setiap agama selalu mengajarkan kebaikan bagi pemeluknya (Hidayat, 2016). Manusia adalah paling sempurna yang memiliki kemampuan untuk mengetahui segala sesuatu yang baik dan buruk, mampu membedakannya, serta menyadari konsekuensi dari pilihannya tersebut (Wahyu, 2010).

\section{Gaya Hidup}

Menurut Kotler dan Armstrong (2008) gaya hidup adalah pola hidup seseorang yang diekspresikan dalam kegiatan, minat, dan pendapatnya. Gaya hidup melibatkan pengukuran dimensi AIO (activities, interest, opinions).Orang yang berasal dari subbudaya, kelas sosial, dan pekerjaan yang sama mungkin mempunyai gaya hidup yang cukup berbeda. Gaya hidup menangkap sesuatu yang lebih dari sekedar kelas sosial atau kepribadian seseorang.Gaya hidup menampilkan profil seluruh pola tindakan dan interaksi seseorang di dunia. Jika digunakan secara cermat, konsep gaya hidup dapat membantu pemasar memahami nilai konsumen yang berubah dan bagaimana gaya hidup mempengaruhi perilaku pembelian. Gaya hidup bersifat tidak permanen dan cepat berubah menyesuaikan perubahan yang terjadi.Gaya hidup pada setiap individu tidak dapat disamakan mengingat selera masing-masing individu berbeda.

\section{Harga}

Secara sederhana harga dapat didefinisikan oleh Sumarwan (2018) yang merupakan salah satu unsur bauran pemasaran yang dapat dikendalikan oleh perusahaan. Penetapan harga sebuah produk menjadi salah satu keputusan strategis perusahaan yang harus dilakukan dengan tepat karena harga akan menentukan penjualan produk sekaligus akan mempengaruhi pendapatan perusahaan. Harga akan dipandang sebagai indikator kualitas sebuah produk. Kemungkinan besar resiko yang akan dihadapi pelaku usaha jika keliru dalam penetapan harga yang tidak sesuai dengan kebutuhan pasar maka hanya sebagian kecil produk dapat diterima di pasaran (Rachmawati, et al., 2020). 
Cl, Pl/Tll Iurnal Kajian Ekonomi \& Bisnis Islam

Vol 4 No 2 (2021) 174-186 P-ISSN 2620-295 E-ISSN 2747-0490

DOI: $1047467 /$ elmal.v4i2.535 


\section{KERANGKA BERPIKIR}

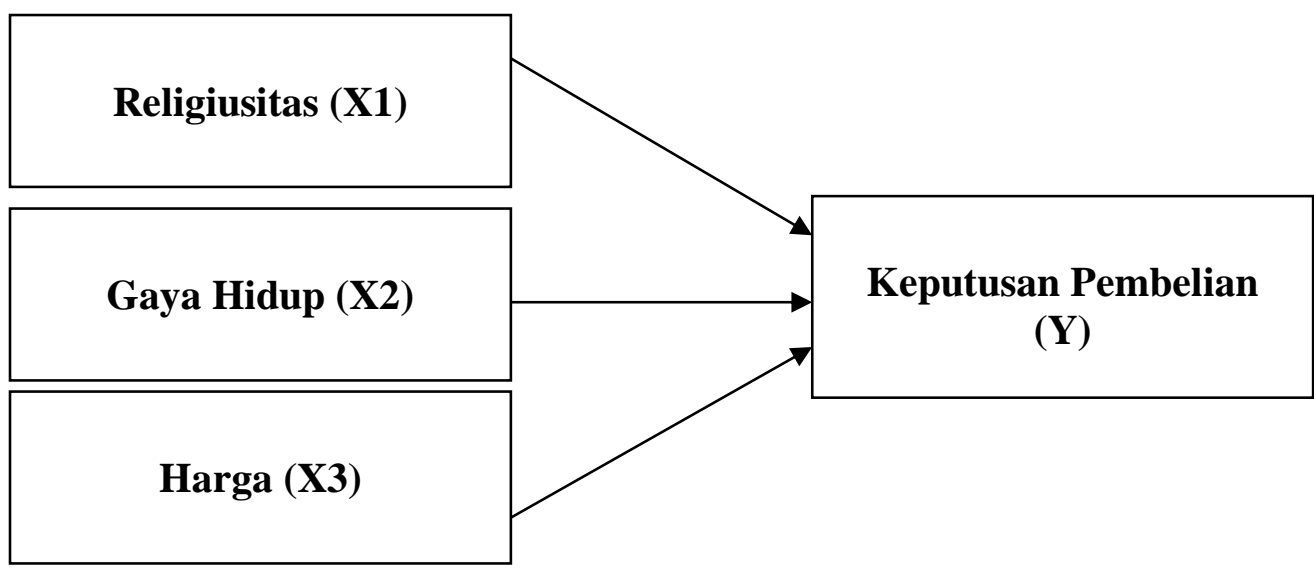

\section{METODE PENELITIAN}

\section{Populasi}

Populasi pada penelitian ini yaitu pengguna Marketplace yang berdomisili di Jakarta maupun Bogor dan telah melakukan pembelian produk busana muslim khususnya pada aplikasi Shopee.

\section{Sampel}

Sampel yang diperoleh dari hasil perhitungan berjumlah 96 responden.Besarnya jumlah sampel tersebut dibulatkan menjadi 100 responden yang dirasa cukup mewakili populasi tersebut.Penelitian ini menggunakan teknik pengambilan sampel dengan purposive sampling yang merupakan bagian dari teknik non probability sampling.

\section{Teknik Pengumpulan Data}

Teknik pengumpulan data dalam penelitian ini menggunakan kuesioner dengan bantuan google-form dan disebar secara online.Kuesioner yang diberikan kepada responden berupa pertanyaan tertutup dengan jawaban yang terbatas atau jawaban yang telah disediakan.Skala pengukuran tiap variabel penelitian menggunakan skala Likert dengan interval 1-5.

\section{Teknik Analisis Data}

Teknik analisis data yang digunakan dalam penelitian ini adalah regresi linear berganda. Analisis ini digunakan untuk menguji pengaruh satu atau lebih variabel independen terhadap variabel dependen yang bertujuan untuk meramalkan bagaimana naik turunnya variabel dependen, 


\section{Vol 4 No 2 (2021) 174-186 P-ISSN 2620-295 E-ISSN 2747-0490 DOI: $1047467 /$ elmal.v4i2.535}

\section{HASIL DAN PEMBAHASAN}

\section{Uji Normalitas}

Uji normalitas metode Kolmogorov-Smirnov merupakan bagian dari uji asumsi klasik yang bertujuan untuk mengetahui data yang diperoleh berdistribusi normal atau tidak. Model regresi yang baik memiliki nilai signifikan yang berdistribusi normal. Hasil uji normalitas dapat dilihat pada tabel berikut ini.

Tabel 1. Hasil Uji Normalitas

\section{One-Sample Kolmogorov-Smirnov Test}

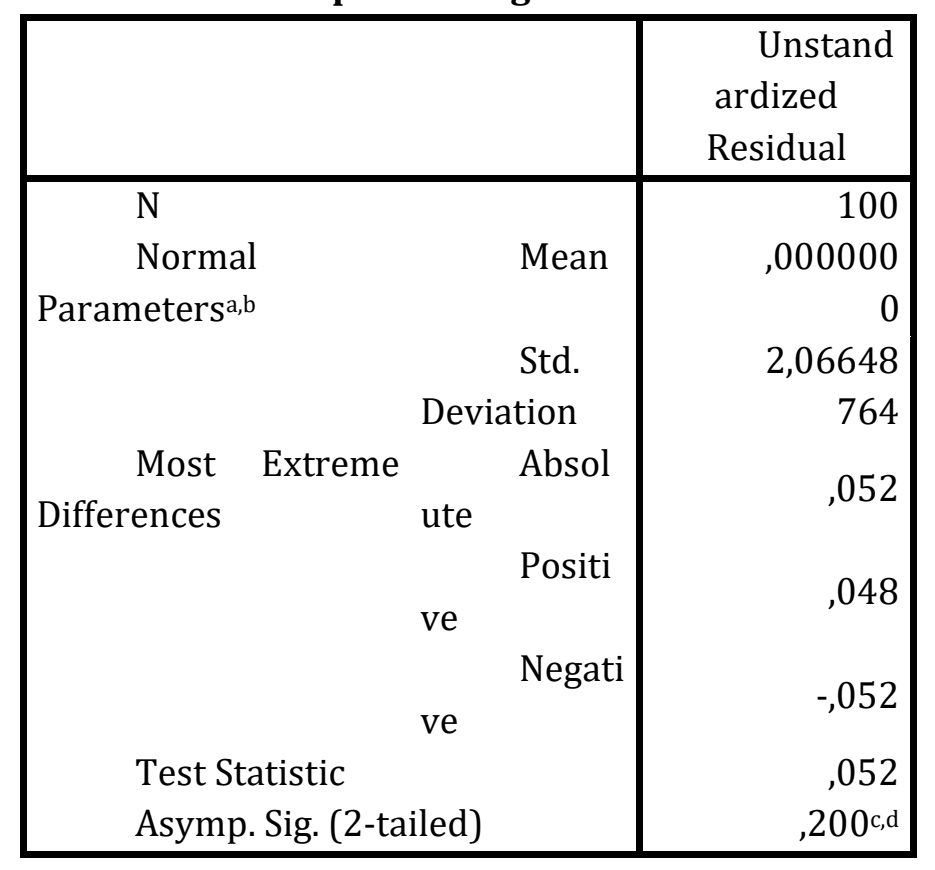

Berdasarkan tabel 1 diatas, dari hasil uji normalitas pada uji Kolmogorov-Smirnov dapat diketahui bahwa nilai signifikan 0,200 > 0,05 maka dapat disimpulkan bahwa data berdistribusi normal.

\section{Uji Multikolinieritas}

Uji ini dilakukan untuk mengetahui ada atau tidaknya gejala multikolinieritas dengan ketentuan apabila nilai VIF $<10$ dan nilai tolerance $>0,1$ maka dapat dinyatakan tidak terjadi multikolinieritas. Hasil uji multikolinieritas dapat dilihat pada tabel berikut ini. 
Vol 4 No 2 (2021) 174-186 P-ISSN 2620-295 E-ISSN 2747-0490

DOI: $1047467 /$ elmal.v4i2.535

Tabel 2. Hasil Uji Multikolinieritas

\begin{tabular}{|c|c|c|}
\hline \multicolumn{3}{|c|}{ Coefficients $^{a}$} \\
\hline \multirow[b]{2}{*}{ Model } & \multicolumn{2}{|c|}{$\begin{array}{l}\text { Collinearity } \\
\text { Statistics }\end{array}$} \\
\hline & $\begin{array}{l}\text { Tole } \\
\text { rance }\end{array}$ & $\mathrm{F}^{\mathrm{VI}}$ \\
\hline (Constant) & & \\
\hline RELIGIUSITAS & ,901 & $\begin{array}{r}1, \\
110\end{array}$ \\
\hline GAYA HIDUP & ,565 & $\begin{array}{r}1, \\
770\end{array}$ \\
\hline HARGA & ,533 & $\begin{array}{r}1, \\
876\end{array}$ \\
\hline
\end{tabular}

Berdasarkan tabel 2 diatas, dari hasil uji multikolinieritas dapat diketahui bahwa variabel religiusitas memiliki nilai VIF 1,110 dan tolerance 0,91, variabel gaya hidup memiliki nilai VIF 1,770 dan tolerance 0,56, dan variabel harga memiliki nilai VIF 1,876 dan tolerance 0,53. Maka dapat dinyatakan bahwa model regresi tidak terjadi multikolinieritas karena masing-masing variabel independen berada diatas 0,1 dan nilai VIF dibawah 10.

\section{Uji Heteroskedastisitas}

Uji heteroskedastisitas bertujuan untuk mengetahui ada atau tidaknya kesamaan variabel dari nilai residual untuk semua pengamatan pada model regresi. Model regresi yang baik ditandai dengan tidak terjadi heteroskedastisitas. Cara untuk mengetahuinya adalah dengan melihat grafik Scatterplot. Jika pola tidak beraturan atau menyebar diatas dan dibawah 0 pada sumbu Y maka tidak terjadi heteroskedastisitas. Hasil uji heteroskedastisitas dapat dilihat pada grafik berikut ini.

\section{Grafik 1. Hasil Uji Heteroskedastisitas}




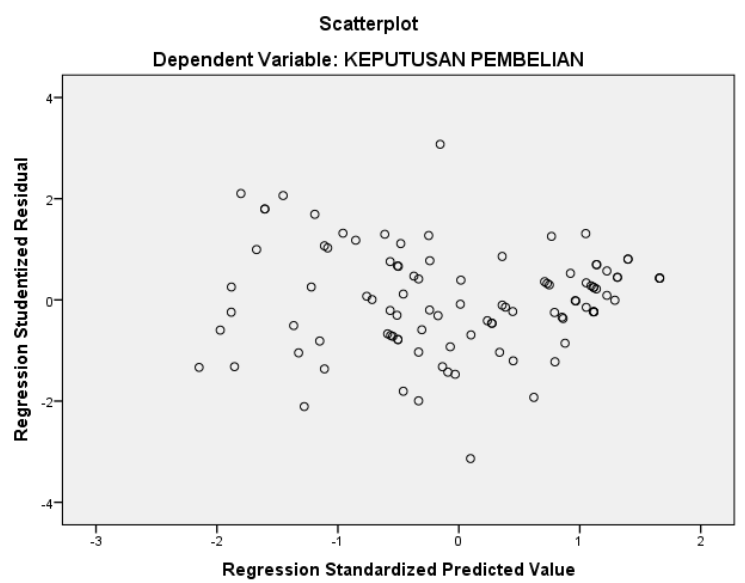

Berdasarkan grafik 1 diatas, dari hasil uji heteroskedastisitas dapat diketahui bahwa pola tidak terbentuk dengan jelas dan menyebar diatas maupun dibawah titik 0 sehingga tidak terjadi heteroskedastisitas.

\section{Analisis Regresi Linier Berganda}

Analisis regresi linear berganda bertujuan untuk mengetahui pengaruh dua atau lebih variabel independen (X) terhadap dependen keputusan pembelian (Y). Hasil analisis regresi linear berganda dapat dilihat pada tabel berikut ini :

Tabel 3. Hasil Analisis Regresi Linier Berganda

\begin{tabular}{|c|c|c|c|}
\hline \multicolumn{4}{|c|}{ Coefficients $^{\mathbf{a}}$} \\
\hline \multirow[b]{2}{*}{ Model } & & \multicolumn{2}{|c|}{$\begin{array}{l}\text { Unstandardized } \\
\text { Coefficients }\end{array}$} \\
\hline & & B & $\begin{array}{l}\text { Std. } \\
\text { Error }\end{array}$ \\
\hline 1 & (Constant) & 4,615 & $\begin{array}{r}5,05 \\
?\end{array}$ \\
\hline & RELIGIUSITAS (X1) & ,064 & 151 \\
\hline & GAYA HIDUP (X2) & 262 & ,075 \\
\hline & HARGA (X3) & ,776 & ,099 \\
\hline
\end{tabular}

Berdasarkan tabel 3 diatas, dapat dilihat nilai konstanta sebesar 4,165 sehingga dapat diperoleh persamaan regresi linear berganda sebagai berikut :

$$
\mathrm{Y}=4,615+0,64 \mathrm{X}_{1}+0,262 \mathrm{X}_{2}+0,776 \mathrm{X}_{3}+\mathrm{e}
$$




\section{Vol 4 No 2 (2021) 174-186 P-ISSN 2620-295 E-ISSN 2747-0490 DOI: 1047467/elmal.v4i2.535}

1) Nilai 0,64 (X1) merupakan nilai koefisien regresi variabel $X 1$ terhadap $Y$ yang artinya jika variabel X1 mengalami peningkatan $1 \%$ maka $\mathrm{Y}$ mengalami peningkatan sebesar $64 \%$

2) Nilai 0,262 (X2) merupakan nilai koefisien regresi variabel $X 2$ terhadap $Y$ yang artinya jika variabel X2 mengalami peningkatan $1 \%$ maka $\mathrm{Y}$ mengalami peningkatan sebesar $26,2 \%$

3) Nilai 0,776 (X3) merupakan nilai koefisien regresi variabel X3 terhadap $Y$ yang artinya jika variabel X3 mengalami peningkatan 1\% maka Y mengalami peningkatan sebesar $77,6 \%$

\section{Hasil Uji Hipotesis}

\section{Uji t}

Uji t digunakan untuk mengetahui ada atau tidaknya pengaruh signifikan variabel bebas (religiusitas, gaya hidup, dan harga) secara parsial terhadap variabel terikat (keputusan pembelian). Uji t dalam penelitian ini menggunakan tingkat signifikan sebesar 0,05. Jika nilai signifikan $\leq 0,05$ maka masing-masing variabel independen berpengaruh signifikan terhadap variabel dependen. Hasil uji t dapat dilihat pada tabel berikut ini.

Tabel 4. Hasil Uji t






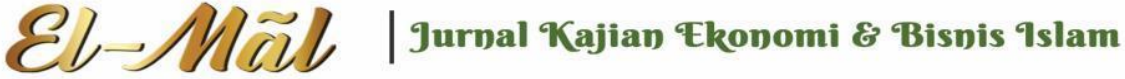

\section{Vol 4 No 2 (2021) 174-186 P-ISSN 2620-295 E-ISSN 2747-0490 DOI: $1047467 /$ elmal.v4i2.535}

Berdasarkan tabel 4 diatas, dari hasil perhitungan analisis uji t adalah sebagai berikut:

1) Diketahui nilai Sig. untuk pengaruh $\mathrm{X} 1$ terhadap $\mathrm{Y}$ adalah sebesar 0,670 > 0,05 sehingga dapat disimpulkan bahwa Hoditerimadan Ha ditolak yang berarti variabel religiusitas (X1) tidak berpengaruh secara signifikan terhadap keputusan pembelian (Y).

2) Diketahui nilai Sig. untuk pengaruh $X 2$ terhadap $Y$ adalah sebesar 0,01 $\leq$ 0,05 dan sehingga dapat disimpulkan bahwa Ho ditolak dan Ha diterima yang berarti variabel gaya hidup (X2) berpengaruh secara signifikan terhadap keputusan pembelian (Y).

3) Diketahui nilai Sig. untuk pengaruh X3 terhadap Y adalah sebesar 0,00 $\leq 0,05$ sehingga dapat disimpulkan bahwa Ho ditolak dan Ha diterima yang berarti variabel harga (X3) berpengaruh secara signifikan terhadap keputusan pembelian (Y).

\section{Uji f}

Uji f dalam penelitian ini digunakan untuk mengetahui ada atau tidaknya pengaruh signifikan variabel bebas (religiusitas, gaya hidup, dan harga) secara simultan terhadap variabel terikat (keputusan pembelian). Jika nilai signifikan $\leq 0,05$ maka terdapat pengaruh variabel bebas secara simultan terhadap variabel dependen. Sebaliknya, Jika nilai signifikan $>0,05$ maka tidak terdapat pengaruh variabel bebas secara simultan terhadap variabel dependen. Hasil uji f dapat dilihat pada tabel berikut ini.

\section{Tabel 5. Hasil Uji f}

\section{ANOVAa $^{a}$}

\begin{tabular}{|c|c|c|c|c|c|}
\hline Model & $\begin{array}{l}\text { Sum of } \\
\text { Squares }\end{array}$ & Df & $\begin{array}{l}\text { Mean } \\
\text { Square }\end{array}$ & $\mathrm{F}$ & ig. \\
\hline Regressi & & & 297,75 & 6 & \\
\hline on & 893,273 & 3 & 8 & 7,614 & $000^{\mathrm{b}}$ \\
\hline Residua & 422,767 & 96 & 4,404 & & \\
\hline Total & $\begin{array}{r}1316,04 \\
0\end{array}$ & 99 & & & \\
\hline
\end{tabular}

Berdasarkan tabel 5 diatas, dari hasil perhitungan analisis uji fadalah nilai signifikan untuk pengaruh X1, X2, X3 secara simultan terhadap Y adalah sebesar 0,000 $\leq$ 0,05 sehingga dapat disimpulkan bahwa Ho ditolak dan Ha diterima yang artinya variabel 


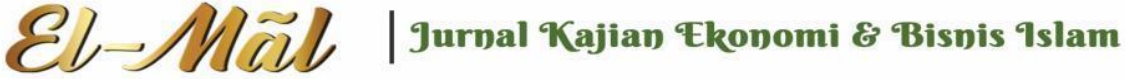

\section{Vol 4 No 2 (2021) 174-186 P-ISSN 2620-295 E-ISSN 2747-0490 DOI: $1047467 /$ elmal.v4i2.535}

religiusitas (X1), gaya hidup (X2), dan harga(X3) secara simultan berpengaruh signifikan terhadap keputusan pembelian (Y).

\section{Uji $\mathbf{R}^{2}$ (Koefisien Determinasi)}

Uji $\mathrm{R}^{2}$ atau koefisien determinasi bertujuan untuk mengetahui seberapa jauh kemampuan variabel independen dalam menjelaskan variabel dependen. Nilai koefisien determinasi ( $R$ Square) dapat dilihat pada tabel berikut ini.

Tabel 6. Hasil Uji Koefisien Determinasi Model Summary

\begin{tabular}{|r|r|r|r|r|}
\hline el & $\mathrm{R}$ & $\begin{array}{r}\mathrm{R} \\
\text { Square }\end{array}$ & $\begin{array}{r}\text { Adjuste } \\
\mathrm{d} \text { R Square }\end{array}$ & $\begin{array}{r}\text { Std. } \\
\text { Error of the } \\
\text { Estimate }\end{array}$ \\
\hline 1 &, $824^{\mathrm{a}}$ &, 679 &, 669 & 2,0985 \\
\hline
\end{tabular}

Berdasarkan tabel 6 diatas, dari hasil perhitungan nilai koefisien determinasi sebesar 0,679 yang artinya variabel keputusan pembelian dapat dijelaskan sebesar $67,9 \%$ oleh variabel religiusitas, gaya hidup, dan harga. Sedangkan sisanya sebesar $33,1 \%$ dijelaskan oleh faktor lain diluar dari pembahasan penelitian. Semakin besar angka koefisien determinasi maka semakin kuat pengaruh antar variabel.

\section{KESIMPULAN DAN SARAN}

\section{Kesimpulan}

Berdasarkan hasil penelitian dan pembahasan dalam bab IV, maka dapat disimpulkan sebagai berikut :

1) Religiusitas tidak berpengaruh secara signifikan terhadap keputusan pembelian produk busana muslim di Marketplace. Hal ini dibuktikan pada nilai signifikan sebesar 0,670 yang artinya Ho diterima dan Ha ditolak. Responden berusia 21-30 tahun merupakan usia paling dominan pada penelitian ini. Faktor usia yang beranjak dewasa memiliki tingkat emosional yang tidak stabil dan cepat berubah. Faktor tersebut dapat berpengaruh terhadap religiusitas seseorang.

2) Gaya hidup berpengaruh secara signifikan terhadap keputusan pembelian produk busana muslim di Marketplace. Hal ini dibuktikan pada nilai signifikan sebesar 0,01 yang artinya Ho ditolak dan Ha diterima. Semakin besar gaya hidup seseorang dalam hal fashion maka akan semakin tinggi pula keputusan pembelian produk busana muslim.

3) Harga berpengaruh secara signifikan terhadap keputusan pembelian produk busana muslim di Marketplace. Hal ini dibuktikan pada nilai signifikan sebesar 0,00 yang 


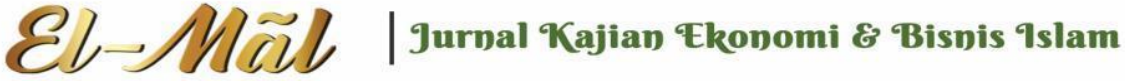

\section{Vol 4 No 2 (2021) 174-186 P-ISSN 2620-295 E-ISSN 2747-0490 DOI: $1047467 /$ elmal.v4i2.535}

artinya Ho ditolak dan Ha diterima. Ada beberapa faktor yang dapat mempengaruhi keputusan pembelian online diantaranya harga yang lebih terjangkau, barang sesuai dengan kualitas yang ditawarkan, daftar harga produk yang jelas, dan banyaknya potongan harga (diskon produk, gratis ongkir, cashback, dll).

4) Religiusitas, gaya hidup, dan harga secara simultan berpengaruh signifikan terhadap keputusan pembelian produk busana muslim di Marketplace. Hal ini dibuktikan pada nilai signifikan sebesar 0,0001 .

\section{Saran}

Berdasarkan hasil penelitian dan pembahasan dalam bab IV, maka dapat disarankan sebagai berikut :

1) Sebagai masyarakat beragama Islam hendaknya selalu mendekatan diri kepada Allah SWT dengan menjalankan segala perintah-Nya dan menjauhi segala larangan-Nya agar senantiasa menjadi pribadi yang berakhlak karimah.

2) Keputusan pembelian pada produk busana muslim di Marketplace dapat dipengaruhi oleh beberapa faktor salah satunya adalah gaya hidup. Penjual (seller) hendaknya mengikuti perkembangan fashion muslim yang sedang diminati atau populer dikalangan masyarakat. Responden berusia 21-30 tahun sangat dominan pada penelitian ini artinya penjual (seller) produk busana muslim hendaknya selalu memperhatikan dan mampu memenuhi standar gaya hidup sebagai penunjang penampilan mereka sehingga dapat menjadi daya tarik tersendiri.

3) Harga merupakan variabel yang berpengaruh besar terhadap keputusan pembelian secara online. Penjual (seller) sebaiknya menetapkan harga yang sesuai dengan kualitas produk agar dapat bersaing dengan yang lain.

4) Bagi peneliti yang akan melakukan penelitian mengenai keputusan pembelian konsumen, diharapkan untuk menambahkan variabel lain agar mendapatkan data yang beragam sehingga faktor-faktor keputusan pembelian konsumen dapat dilihat dari berbagai aspek di luar pembahasan.

\section{DAFTAR PUSTAKA}

Apriyandani, H., Yulianto, E., \& Sunarti, S. (2017). Pengaruh Gaya Hidup Dan Kelompok Referensi Terhadap Keputusan Pembelian (Survei Mahasiswa S1 Fakultas Ilmu Administrasi Angkatan 2014 dan 2015 Universitas Brawijaya Malang yang 




\section{Vol 4 No 2 (2021) 174-186 P-ISSN 2620-295 E-ISSN 2747-0490 DOI: $1047467 /$ elmal.v4i2.535}

Membeli dan Menggunakan Smartphone iPhone). Jurnal Administrasi Bisnis, 50(2), 180-189.

Fahrevi, S. R., \& Satrio, B. (2018). Pengaruh Harga, Promosi, dan Kualitas Pelayanan terhadap Keputusan Pembelian Online di Shopee. co. id. Jurnal Ilmu dan Riset Manajemen (JIRM), 7(3).

Kotler dan Keller. 2008. Prinsip-prinsip Pemasaran. Jilid 1 edisi ke-12. Penerbit Erlangga. Kotler dan Keller. 2019. Manajemen Pemasaran, Jilid 1 edisi ke-13. Penerbit Erlangga.

Lubis, I. S. (2018). Pengaruh religiusitas dan lokasi terhadap keputusan pembelian konsumen pada Rahmat Syariah Swalayan City Walk Padangsidimpuan (Doctoral dissertation, IAIN Padangsidimpuan).

Miatun, S. L., \& Santoso, L. (2020). Pengaruh Religiusitas Terhadap Gaya Hidup Konsumen Muslim Di Ponorogo. SERAMBI: Jurnal Ekonomi Manajemen dan Bisnis Islam, 2(2), 113-120.

Nuraini. (2015). Fesyen Muslim Indonesia : Trade with remarkable Indonesia. Warta Ekspor.

Pitaloka, A. F., \& Widyawati, N. (2015). Pengaruh kualitas pelayanan, harga dan promosi terhadap penjualan online shop busana muslim. Jurnal Ilmu dan Riset Manajemen (JIRM), 4(1).

Putri, A. Z., \& Permatasari, I. R. (2018). Pengaruh Gaya Hidup dan Harga terhadap Keputusan Pembelian Produk Moslem Fashion di Elzatta Kawi Malang. Jurnal Aplikasi Bisnis, 4(1), 225-228.

Rachmawati, A., Kana, A. A., \& Anggarini, Y. (2021). Pengaruh Harga, Kualitas Produk, dan Gaya Hidup terhadap Proses Keputusan Pembelian Produk Hijab di Nadiraa Hijab Yogyakarta. Cakrawangsa Bisnis: Jurnal Ilmiah Mahasiswa, 1(2).

Sumarwan, Ujang, Fandy Tjiptono. (2018). Strategi pemasaran dalam perspektif perilaku konsumen. Bogor: Ipb press

Sumarwan, Ujang. (2011). Perilaku Konsumen Teori dan Penerapannya dalam Pemaasaran. Bogor: Ghalia Indonesia.

Trimulyani, D. (2020). Pengaruh Religiusitas Terhadap Keputusan Pembelian Pakaian Muslimah di Kecamatan Tembilahan (Doctoral dissertation, STAI Auliaurrasyididn Tembilahan).

Wahyu, B. (2010). Filsafat Ekonomi Islam: Rasionalitas dan Religiusitas Ekonomi. Jurnal Ekonomi Islam Al-Infaq, 1(1), 53-60. 